\title{
Percutaneous Venoplasty for Central Venous Stenosis: Effect on Patient's Symptoms and Patency of Arteriovenous Accesses
}

\author{
Zia Ur Rehman1, Abdul Hakeem1, Raza Sayyani2 and Nida Zahid1 \\ Department of Surgery1 / Radiology², The Aga Khan University Hospital, Karachi, Pakistan
}

\begin{abstract}
Objective: To determine symptomatic relief and patency rate of arteriovenous (AV) fistulae and grafts after venoplasty in patients with central venous stenosis (CVS) on hemodialysis.

Study Design: Case series.

Place and Duration of Study: The Aga Khan University Hospital, Karachi, from January 2012 to December 2017.

Methodology: The data of patients who had one session of successful venoplasty for CVS were reviewed. The outcomes measured were symptomatic recovery and improvement in the patency of AV accesses. Symptomatic recovery was termed 'complete', when there was complete symptomatic relief after venoplasty; and 'partial' when the procedure was technically successful, but symptoms were not resolved. Primary patency of AV access was the duration from first intervention till further intervention. Cumulative patency was the total duration of time fistula remains patent with multiple interventions. Events, considered end points to functional access status, were placement of new access site, ligation of access site, dialysis catheter placement or the patient death.

Results: Thirty-five patients had technically successful venoplasty with mean age of $56.86 \pm 14.6$ years. Twenty-one $(60 \%)$ were female patients. All patients tolerated the procedure well. Twenty-one $(60 \%)$ patients had complete relief of symptoms. Fourteen patients ( $40 \%$ ) had partial relief of symptoms. Twenty-one patients required repeat angioplasties. The mean follow-up was $18.6 \pm 9.02$ months. Primary patency was $40 \%, 24 \%, 24 \%$ at 6,12 and 24 months. Cumulative patency was $69 \%, 66 \%$ and $59 \%$ at 6,12 and 24 months.

Conclusion: Percutaneous venoplasty provided symptomatic relief to the patients and improved the short-term patency of $A V$ accesses.
\end{abstract}

Key Words: Central venous stenosis, Venogram, Percuaneous venoplasty, Patency.

How to cite this article: Rehman ZU, Hakeem A, Sayyani R, Zahid N. Percutaneous venoplasty for central venous stenosis: Effect on patient's symptoms and patency of arteriovenous accesses. J Coll Physicians Surg Pak 2019; 29(12):1189-1192.

\section{INTRODUCTION}

A good functioning AV fistula or graft is directly linked to improved quality of life of patients on hemodialysis. Access problems are common and frequent reason of hospitalisation for these patients. 1 The most common issues of hemodialysis accesses are poor flow, thrombosis, bleeding or inadequate dialysis due to central venous stenosis (CVS).

About $11 \%$ to $40 \%$ of the patients on hemodialysis have CVS. ${ }^{2}$ Patients with previous history of central line placement and having AV access on the ipsilateral arm are at risk of developing CVS. ${ }^{3}$ Patients may present with severe arm, neck, and breast oedema. ${ }^{4}$ They also have malfunctioning accesses with inadequate dialysis.

Over the last two decades, percutaneous methods have taken over the surgery for treatment of CVS 5 due to their

Correspondence to: Dr. Zia Ur Rehman, Section of Vascular Surgery, Department of Surgery, The Aga Khan University

Hospital, Stadium Road, Karachi, Pakistan

E-mail: ziaur.rehman@aku.edu

Received: December 18, 2018; Revised: October 18, 2019;

Accepted: Novermber 29, 2019 minimal invasiveness. They are considered to be effective in improving the patency of failing AV accesses, ${ }^{6}$ and also relieving patient's symptoms. There is little reported in loco-regional literature on the outcomes of these procedures. ${ }^{7}$

The objective of this study was to determine the success of percutaneous venoplasty in terms of relieving symptoms of CVS and improving the patency of AV accesses.

\section{METHODOLOGY}

This was a retrospective study conducted at the Aga Khan University Hospital from January 2012 to December 2017. All patients, who had CVS in upper arm or lower leg, were included in the study.

Patients who were lost to follow-up or had incomplete records were excluded from the study. Data about patients' demographics, symptoms, existing co-morbidities, indication for CVS intervention, and location of lesion were retrieved and recorded on specially designed proforma.

All patients had standard percutaneous venoplasties with plain balloons. Technical success was considered when there was less than $30 \%$ residual stenosis. Stenting was 
considered in patients when residual stenosis of more than $50 \%$, with elastic recoil or with complication. Patients were monitored for any post-procedure complications such as bleeding, access site hematoma or access thrombosis. Patients were allowed to use accesses soon after the procedure, if needed. Patients were followed in vascular surgery clinics at 3-month interval.

The outcomes measured were symptomatic recovery and improvement in the patency of arteriovenous access. Symptomatic recovery was termed 'complete', when there was complete symptomatic relief after venoplasty; and 'partial' when the procedure was technically successful but symptoms that led to venoplasty, were not resolved.

Patency of AV accesses were measured as primary and cumulative patency. Primary patency was the duration of time from first intervention to next intervention or fistula failure. Cumulative patency was the total duration of time fistula remain, patent with multiple interventions.

Events considered end points to functional access status were placement of new access site, ligation of access site, dialysis catheter placement or the patient death.

Categorical variables were reported as frequencies along with their percentages. Continuous variables were reported as mean \pm standard deviation. Patency rate was calculated using Kaplan-Meier survival curve. A $p$-value of $<0.05$ was considered as significant. Analyses were performed using SPSS version 22 (IBM Inc.).

\section{RESULTS}

During the study period, 48 patients had attempted venoplasty. Thirteen patients were excluded as wire was not negotiable through the lesion. Thirty-five patients had technically successful venoplasty. The mean age

Table I: Demographics of patients and details of arteriovenous accesses.

\begin{tabular}{lc}
\hline $\mathrm{N}=35$ & Number $(\%)$ \\
\hline Comorbidities & $34(97.1)$ \\
Hypertension & $16(45.7)$ \\
Diabetes mellitus & $8(22.9)$ \\
Coronary artery disease & $5(14.3)$ \\
Hepatitis C & $2(5.7)$ \\
Polycystic kidney disease & $3(8.6)$ \\
Hypothyroidism & $3(8.6)$ \\
Systemic lupus erythrosclerosis & \\
\hline Site of fistula & $24(68.6)$ \\
Left arm & $9(25.7)$ \\
Right arm & $1(2.9)$ \\
Left leg & $1(2.9)$ \\
Right leg & \\
\hline Site of stenosis & $8(22.9)$ \\
Axillary vein & $9(25.7)$ \\
Subclavian vein & $16(45.7)$ \\
Brachiocephalic vein & $1(2.9)$ \\
External lliac vein & $1(2.9)$ \\
Common Iliac vein &
\end{tabular}

of the patients was $56.86 \pm 14.6$ years. Most of them were females $(21,60 \%)$. The major comorbidities were hypertension and diabetes (Table I). Twenty-four $(68.6 \%)$ patients had native arteriovenous fistula, while $11(31.4 \%)$ had arteriovenous grafts.

Twenty-three $(65.7 \%)$ patients presented with arm swelling, $10(28.6 \%)$ patients with poor flow, and $2(5.7 \%)$ patients with increased pressure during dialysis.

The most common sites of stenosis were brachiocephalic vein followed by subclavian vein. One patient had balloon leak, while another patient had cardiac event in post-procedure day, which settled with medical management.

Twenty-one $(60 \%)$ patients had initial complete relief of symptoms and $14(40 \%)$ patients had partial relief. Primary patency was $40 \%, 24 \%, 24 \%$ at 6,12 and 24 months. Cumulative patency was $69 \%, 66 \%$ and $59 \%$ at 6, 12 and 24 months (Figures 1 and 2).

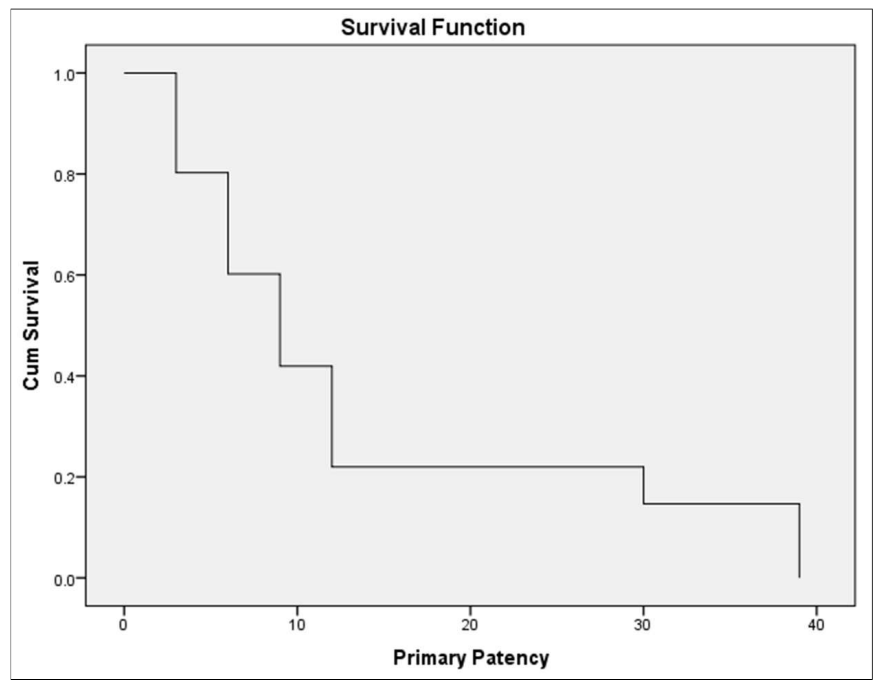

Figure 1: Graph showing primary patency of arteriovenous accesses.

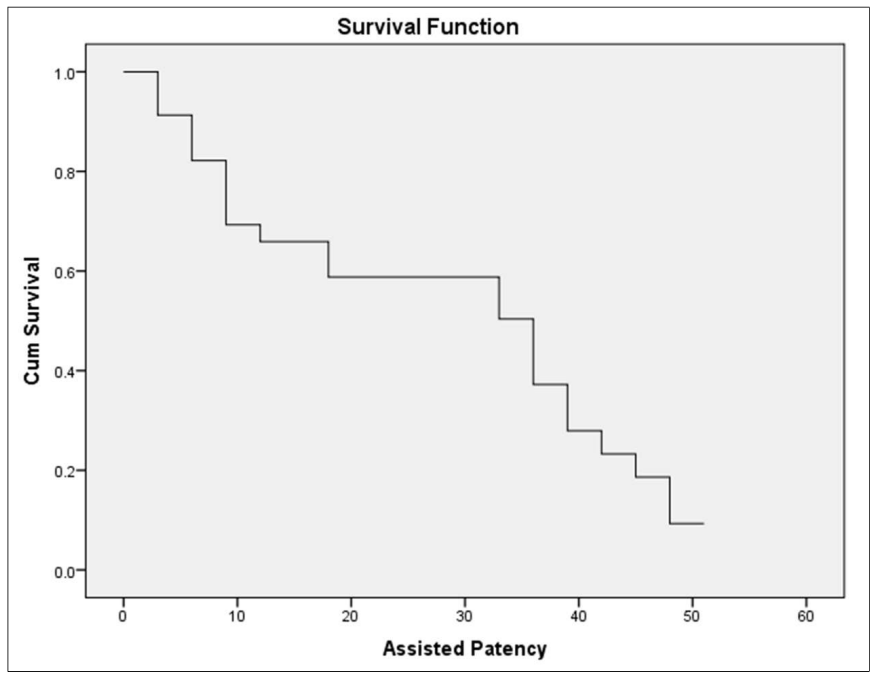

Figure 2: Graph showing cumulative patency of arteriovenous accesses. 
Twenty-six (74\%) patients had recurrence of symptoms. Twenty-one $(60 \%)$ patients underwent repeat angioplasty. Five patients $(14 \%)$ had surgical management for CVS. Ligation and formation of new AVF in one patient; two patients had thrombectomies, while two patients had bypass procedures for relieving CVS. Four patients had stents placed. One stent was placed at the time of first angioplasty and three were placed at the time of the repeated venoplasty sessions.

\section{DISCUSSION}

The present study showed that CVS venoplasty improved patients' symptoms and also improved the short term patency of vascular access. Seventy-four percent patients had recurrence in which most patients required repeated venoplasty. There were no major complication encountered. All accesses were usable for dialysis soon after the procedure.

Bakken et al. showed improved haemodialysis access patency of $77 \%, 73 \%$ and $57 \%$ at 3, 12 and 24 months after CVS venoplasty. 8 Bountouris et al. also noted patency of $42 \%$ at 24 months. 9 Glanz $S$ et al. noted 1 -year patency rate of $35 \% .10$ The results are consistent with this study. Ya et al. showed, PTA for CVC achieved technical success in $92 \%$ of cases, and symptoms were initially alleviated in $96 \%$ of subjects. ${ }^{11}$ Others have also documented the efficiency of this modality. ${ }^{12}$ The authors also found it effective in relieving patients arm swelling.

Many authors have highlighted the issue of recurrence after initial venoplasty and considered it a norm. Ya et al. showed recurrence rate of $58 \%$ at 4 months after PTA. 11 Same were the findings of the Sprouse et al. and Argarwal et al.13,14 Inflating the balloon itself caused local intimal injury and may induce neointimal hyperplasia, hence recurrent venous stenosis.

Plain balloons were used but better patency may be achievable with cutting balloons, 15 drug-eluting balloons, ${ }^{16}$ or specialised high pressure balloons. These were neither available nor feasible due to higher cost.

The use of stents is controversial during intervention. Many of the previous studies fail to demonstrate whether stenting provides additional benefit or not. Stents were offered only to those patients who had elastic recoil or had significant persistent stenosis. There have been studies which document better patency rates following stenting. However, long term patency is not seen in all cases. Quinn et al. compared stenting with PTA alone and saw that patency rates were comparative in both cases.17 Oderich et al. reported that primary patency remains same at one year and re-intervention rate is not better than the presently reported results. ${ }^{18}$

The limitations of this study include being a retrospective, collection of data from a single institute with limited number of patients. Despite this, it showed the efficiency of PTA in relieving arm oedema and improving short term longevity of AV accesses.

\section{CONCLUSION}

Percutaneous venoplasty for CVS can provide symptomatic relief in majority of the patients and can improve the short term patency of arteriovenous access.

\section{ETHICAL APPROVAL:}

Being a retrospective study, it was exempted from Institutional Ethical Review Committee approval.

\section{PATIENTS' CONSENT:}

All patients gave informed consent for using of their data for research purpose at the time of index procedure.

\section{CONFLICT OF INTEREST:}

Authors declared no conflict of interest.

\section{AUTHORS' CONTRIBUTION:}

ZUR: Study concept, data collection and interpretation, manuscript writing, revision, critical review, final approval and accountability of all aspects of the work.

$\mathrm{AH}$ : Data collection and interpretation, manuscript writing, final approval and accountability of all aspects of the work. RS: Critical review, final approval and accountability of all aspects of the work.

NZ: Data Interpretation, final approval and accountability of all aspects of the work.

\section{REFERENCES}

1. Mudoni A, Cornacchiari M. Arteriovenous fistula stenosis and percutaneous transluminal angioplasty: How, when and why? J Clin Exp Nephrol 2017; 2:47.

2. Surratt RS, Picus D, Hicks ME, Darcy MD, Kleinhoffer M, Jendrisak M. The importance of preoperative evaluation for the subclavian vein in dialysis access planning. AJR Am J Roentgenol 1991; 156:623-5.

3. Khali MA, Rabbani MS, Chima NR, Tan J, Khalil MA, Rehman ZU. Recurrent brachiocephalic vein stenosis as a cause for persistent left-sided transudative pleural effusion in a hemodialysis patient. Ann Vasc Surg 2016; 35:208.

4. Kundo S. Review of central venous disease in hemodialysis patients. J Vasc Inter Radiol 2010; 21:963-8.

5. Vesely TM, Hovsepian DM, Pilgram TK, Coyne DW, Shenoy S. Upper extremity central venous obstruction in hemodialysis patients: Treatment with Wallstents. Radiology 1997; 204:343-8.

6. Kim WS, Pyun W1B, Kang BC. The primary patency of percutaneous transluminal angioplasty in hemodialysis patients with vascular access failure. Korean Circulation J 2011; 42:512-7.

7. Ashraf T, Mengal N, Khan NU, Akhtar P. Central venoplasty in AV (Arteriovenous) fistula dysfunction a palliative endovascular approach. J Pak Med Assoc 2017; 67:1943-45.

8. Bakken AM, Protack CD, Saad WE, Lee DE, Waldman DL, Davies MG. Long term outcomes of primary angioplasty and primary stenting of central venous stenosis in hemodialysis patients. J Vasc Surg 2007; 45:776-83.

9. Bountouris I, Kristmundsson T, Dias N, Zdanowski Z, Malina M. Is repeat PTA of the failing Hemodialysis fistula durable? Int $\mathrm{J}$ Vasc Med 2014; 2014:369687. 
10. Glanz S, Gordon DH, Lipkowitz GS, Butt KM, Hong J, Sclafani SJ. Axillary and subclavian vein stenosis: Percutaneous angioplasty. Radiology 1988; 168:371-3.

11. Yan Y, Sudheendra D, Dagli MS, William Stavropoulos S, Clark TW, Soulen MC. Effect of central venous angioplasty on hemodialysis access circuit flow: Prospective study of $25 \mathrm{symp}-$ tomatic patients. J Vasc Interv Radiol 2015; 26:984-91.

12. Ashwal AJ, Abdul Razak UK, Padmakumar R, Umesh Pai, Sudhakar M. Percutaneous intervention for symptomatic central vein stenosis in patients with upper limb arteriovenous dialysis access. Indian Heart J 2018; 70:690-8.

13. Sprouse LR 2nd, Lesar CJ, Meier GH 3rd, Parent FN, Demasi RJ, Gayle RG, et al. Percutaneous treatment of symptomatic central venous stenosis. J Vasc Surg 2004; 39:578-82.

14. Agarwal AK, Patel BM, Hadd NJ. Central vein stenosis: A nephrologist's prospective. Semin Dial 2007; 20:53-62.
15. Saleh HM, Gabr AK, Tawfik MM, Abouellail H. Prospective, randomized study of cutting balloon angioplasty versus conventional balloon angioplasty for the treatment of hemodialysis access stenosis. J Vasc Surg 2014; 60:735-40.

16. Bountouris I, Kritikou G, Degermetzoglou N, Avgerinos KI. A review of percutaneous transluminal angioplasty in hemodialysis fistula. Int J Vasc Med 2018; 27;1420136.

17. Quinn SF, Schuman ES, Demlow TA, Standage BA, Ragsdale JW, Green GS, et al. Percutaneous trans-luminal angioplasty versus endovascular stent placement in the treatment of venous stenosis in patients undergoing hemodialysis: Preliminary results. J Vasc Interv Radiol 1995; 6:851-5.

18. Oderich GS, Treiman GS, Schneider P, Bhirangi K. Stent placement for treatment of central and peripheral venous obstruction: A long-term multi-institutional experience. $J$ Vasc Surg 2000; 32:760-9. 